\title{
Gastric Perforation Due to Blunt Trauma Abdomen
}

\author{
Rattan KN' , Aggarwal M², Bansal S3 , Gurupriya J4
}

\begin{abstract}
Blunt trauma abdomen rarely leads to gastrointestinal injury in children and isolated gastric rupture is even rarer presentation. We are reporting a case of isolated gastric rupture after fall from height in a three year old male child.
\end{abstract}

Key words: Gastrointestinal, Abdomen, Stomach
${ }^{1}$ Dr. KN Rattan, MBBS. MD. Senior Professor and Head of department of Paediatric Surgery, ${ }^{2}$ Dr. Mansi Aggarwal, MBBS. MD. Senior Resident, Department of Pathology, ${ }^{3}$ Dr. Shruti Bansal, MBBS. MD Resident, Department of Pathology, ${ }^{4} \mathrm{Dr}$. Gurupriya J, MBBS. MD Resident, Department of Pathology. All from the Pandit Bhagwat Dayal Sharma University of Health Sciences, Post Graduate Institute of Medical Sciences, Rohtak, Haryana, India.

\section{Address for correspondence \\ Dr. Shruti Bansal \\ E-mail: shruti.b.bansal3@gmail.com}

\section{How to cite}

Rattan KN, Aggarwal M, Bansal S, Gurupriya J. Gastric Perforation Due to Blunt Trauma Abdomen. J Nepal Paediatr Soc 2017;37(3):284-285. height. The child was conscious, however clammy and dehydrated. Physical examination revealed mild tachycardia. Blood pressure was 100/65 mmHg. Local examination showed tenderness and guarding of upper abdomen along with abdominal wall dimple. Immediate chest and abdominal X-rays were done which showed gas under diaphragm and multiple air- fluid levels. There was no evidence of other acute chest injuries. CECT abdomen showed massive pneumoperitoneum with haemo-peritoneum. The patient was resuscitated and was shifted for exploratory laparotomy in emergency OT. A $4 \mathrm{~cm}$ long full thickness gastric rupture was found along the greater curvature of stomach. There was no associated visceral tear or rupture (Figure 1). Primary two layer closure was performed. A thorough peritoneal lavage was done. Post- operative recovery was uneventful and patient was asymptomatic on two months follow- up.
This work is licensed under a Creative Commons Attribution 3.0 License.

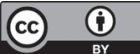




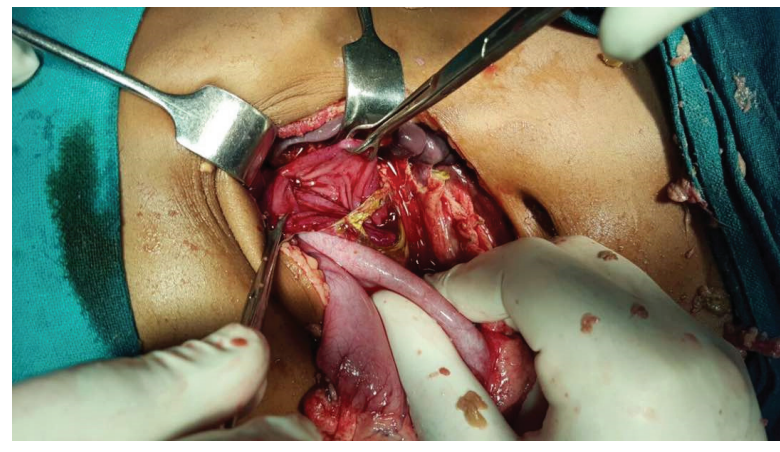

Fig 1: Intraoperative picture of the case.

\section{Discussion}

Idiopathic gastric rupture is rare in children beyond neonatal period; explained by the extensive mobility, distensibility and deeper location of the organ in the rib cage $^{3}$. However, stomach is more vulnerable to rupture if distended by food, liquid or gas. Gastric rupture following trauma abdomen usually occurs along with other viscera rupture or tear. The organs frequently involved in simultaneous injury are liver, spleen, pancreas, lungs and injuries involving extremities ${ }^{4}$.

Gastrointestinal organ injuries can occur by three mechanisms: crush injury, burst injury and shear injury. In the former, the organ is compressed violently against the spine. Rapid compressive forces when applied to distended hollow viscous cause burst injury. Shear injury is caused by continuous acceleration and deceleration of the organ at point of fixation as can occur during Heimlich maneuver ${ }^{5}$. The most common cause of rupture is blunt trauma abdomen due to motor vehicle collision accounting for $75 \%$ of the cases. Others include can be assaults, falls, psychiatric disorders, like anorexia nervosa ${ }^{1,6}$.

\section{References}

1. Pafitanis G, Koulas S, Bikos S, Tsimoyiannis E. Paediatric case of a large gastric rupture after a blunt abdominal trauma: Report of a case in a District General Hospital. Int J Surg Case Rep. 2013;4:235-7. DOI: https://doi.org/10.1016/j.jisscr.2012.11.013

2. Roupakias S, Tsikopoulos G, Stefanidis C, Skoumis $\mathrm{K}$, Zioutis I. Isolated double gastric rupture caused by blunt abdominal trauma in an eighteen months old child: A case report. Hippokratia. 2008;12:50-2.

3. Libeer F, Vanhamel N, Huyghe M, Verlinden E. Spontaneous gastric rupture in non-neonatal children
The rupture can be full thickness or partial thickness. Full thickness rupture first involves the seromuscular layer followed by submucosa and mucosa, respectively. The most common site of rupture is anterior gastric wall followed by greater curvature, lesser curvature and the posterior gastric wall ${ }^{4}$. In our case, the child was diagnosed as having rupture at greater curvature of stomach.

Owing to the rarity and even rarer isolated occurrence of rupture stomach, making its diagnosis is difficult and requires a high index of suspicion ${ }^{4}$. Delay in diagnosis is associated with higher morbidities and mortalities. Prompt abdominal and chest X-rays can be done but free intraperitoneal air is visible in only $16-66 \%$ of the cases. CT may be helpful in early diagnosis and thereby decrease the resultant mortality due to peritoneal contamination, sepsis and shock. Intraperitoneal air and associated solid organ injuries are better visualised on $\mathrm{CT}^{2}$. In our patient, multiple air- fluid levels were visualised on X-ray and CT revealed gastric tear.

Closing the tear in two layers is the treatment of choice for gastric rupture. It should be followed by air test to assess the subtleness of repair and looking out for any other sustained gastric rupture ${ }^{2}$. In our case also, the tear was sutured in two layers followed by air test. No other simultaneous gastric tear was found. Thorough peritoneal lavage and drainage was done before closing the abdomen.

\section{Conclusion}

Isolated gastric rupture is extremely rare in children. Keeping its possibility as a differential is essential on part of the clinician to aid the early diagnosis and treatment and minimise the associated complications and mortality.
: a case report. Acta Chir Belg. 2007;107:560-63. DOI: https://doi.org/10.1080/00015458.2007.11680124

4. Hota PK, Babu M, Satyam G and Praveen C. Traumatic gastric rupture following blunt trauma abdomen: a case series. BMJ. 2014;3:49-52. DOI: 10.15562/bmj.v3i1.71

5. Steven S, Pearl RH. Abdominal trauma. In: Grosfeld JL, O'Neal SA Jr, Fonkalsrud EW, Coran AG, editors. Pediatr Surgy. 6th ed. 2006. pp. 295-316.

6. Hashmi KS, Ellul T, Leopard DC, Woodward A. Spontaneous gastric perforation in an 11-year-old boy with anorexia nervosa: rare presentation with right iliac fossa pain. BMJ case reports 2012;2012:bcr-2012. DOI:10.1136/bcr-2012-006512. 